\title{
CONSUMPTION- AND PRODUCTIVITY-ADJUSTED DEPENDENCY RATIO WITH HOUSEHOLD STRUCTURE HETEROGENEITY
}

Xuehui Han and Yuan Cheng

NO. 531

December 2017
ADB ECONOMICS WORKING PAPER SERIES 
ADB Economics Working Paper Series

\section{Consumption- and Productivity-Adjusted Dependency Ratio with Household Structure Heterogeneity}

Xuehui Han and Yuan Cheng

No. 531 | December 2017
Xuehui Han (xuehuihan@adb.org) is an economist at the Economic Research and Regional Cooperation Department, Asian Development Bank. Yuan Cheng (chengyuan@fudan.edu.cn) is a professor at the Institute of Population Research, Fudan University.

The authors are grateful for comments from Joseph Ernest Zveglich Jr., Arief Ramayandi, Jesus Felipe, Feinian Chen, Zhencao Qian, Yong Cai, and the participants at the Population Association of America 2015 Annual Meeting; and the excellent research assistance provided by Orlee P. Velarde and Ma. Christina Epetia. The authors are responsible for any remaining errors in the paper. 
(C) 2017 Asian Development Bank

6 ADB Avenue, Mandaluyong City, 1550 Metro Manila, Philippines

Tel +632632 4444; Fax +6326362444

www.adb.org

Some rights reserved. Published in 2017

ISSN 2313-6537 (Print), 2313-6545 (electronic)

Publication Stock No. WPS179182-2

DOI: http://dx.doi.org/10.22617/WPS179182-2

The views expressed in this publication are those of the authors and do not necessarily reflect the views and policies of the Asian Development Bank (ADB) or its Board of Governors or the governments they represent.

ADB does not guarantee the accuracy of the data included in this publication and accepts no responsibility for any consequence of their use. The mention of specific companies or products of manufacturers does not imply that they are endorsed or recommended by ADB in preference to others of a similar nature that are not mentioned.

By making any designation of or reference to a particular territory or geographic area, or by using the term "country" in this document, $A D B$ does not intend to make any judgments as to the legal or other status of any territory or area.

This work is available under the Creative Commons Attribution 3.0 IGO license (CC BY 3.0 IGO)

https://creativecommons.org/licenses/by/3.0/igo/. By using the content of this publication, you agree to be bound by the terms of this license. For attribution, translations, adaptations, and permissions, please read the provisions and terms of use at https://www.adb.org/terms-use\#openaccess

This CC license does not apply to non-ADB copyright materials in this publication. If the material is attributed to another source, please contact the copyright owner or publisher of that source for permission to reproduce it. $A D B$ cannot be held liable for any claims that arise as a result of your use of the material.

Please contact pubsmarketing@adb.org if you have questions or comments with respect to content, or if you wish to obtain copyright permission for your intended use that does not fall within these terms, or for permission to use the ADB logo.

Notes:

In this publication, "\$” refers to US dollars.

ADB recognizes "China" as the People's Republic of China and "America" as the United States.

Corrigenda to ADB publications may be found at http://www.adb.org/publications/corrigenda. 


\section{CONTENTS}

TABLES AND FIGURES

ABSTRACT

$\begin{array}{lll}\text { I. INTRODUCTION } & 1\end{array}$

II. CONSUMPTION-AND PRODUCTIVITY-ADJUSTED DEPENDENCY RATIO 2

$\begin{array}{ll}\text { III. } & 4\end{array}$

IV. EMPIRICAL ESTIMATIONS OF CONSUMPTION-

AND PRODUCTIVITY-ADJUSTED DEPENDENCY RATIO

V. HOUSEHOLD CONSUMPTIONS AND CORESIDENCE STYLE IN THE PEOPLE'S REPUBLIC OF CHINA

VI. CONSUMPTION SIMULATIONS IN THE PEOPLE'S REPUBLIC OF CHINA

A. $\quad$ Time Trend of Traditional and Adjusted Dependency Ratios 12

B. What is the Impact on Household Consumption when Households

Become Smaller?

C. What is the Impact on Household Consumption of Immigration from Rural to Urban Areas?

D. What is the Impact of Economic Growth that is Associated to Aging on Household Consumption?

VII. CONCLUSION

APPENDIX

REFERENCES 


\section{TABLES AND FIGURES}

\section{TABLES}

1 Regression of Consumption on Household Age Components 5

2 Regression of Income on Household Age Components 5

3 Estimated Consumption and/or Income Equivalent Unit 7

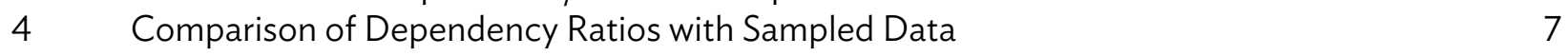

$5 \quad$ Household Consumptions and Coresidence Styles 11

\section{FIGURES}

$1 \quad$ Relations between Household Consumption and Income Conditional on Household Size $\quad 8$

2 Distributions of Household Consumptions by Size and Household Age Structures 9

3 Time Trends of Traditional and Adjusted Dependency Ratios 


\begin{abstract}
In this study, we construct a new dependency ratio measure by taking into account the consumption needs of the young and elderly people, and the productivity of middle-aged people. Different from the way that Cutler et al. (1990) and Weil (1999) constructed the relative needs by using the average consumptions of each age cohort of people, we estimate the factor of relative needs of people at different ages based on a regression model, which embraces the household age compositions and size in the assessment. Our analysis uses household survey data from five developing countries in AsiaBangladesh, Cambodia, the People's Republic of China (PRC), Thailand, and Viet Nam. To our best knowledge, this is among the pioneer work exploring such patterns for these countries. Focusing on the PRC, we further examine whether consumptions depend on the coresidence style. We found that (i) the consumption- and productivity-adjusted dependency ratio (both total and old dependency ratios) are consistently lower than the one that is traditionally defined across all five countries in our sample, and the differences vary from country to country; (ii) in the PRC, the differences between traditional dependency ratio and the consumption- and productivity-adjusted dependency ratio grow larger in more distant future; and (iii) in the PRC, the relatively younger elderly members between 65 and 72 years old help in reducing the consumption of young members in their households, and the elderly members who live alone consume more than their peers who live with their offspring. We also simulate the impacts of smaller households, urbanization, and economic growth on consumption for the PRC, based on our model.
\end{abstract}

Keywords: consumption- and productivity-adjusted dependency ratio, coresidence, household structure

JEL codes: D10, E10, E21, H55, J11 


\section{INTRODUCTION}

Dependency ratio, especially old dependency ratio, has been widely used as an indicator to monitor a population's age structure and its implication on socioeconomic development. Among the implications, the most important consideration is the savings-driven economic growth and the sustainability of the pension system. The former affects economic growth and the latter impacts on society's stability.

The effort of incorporating the different needs of people at different ages into the dependency ratio goes back to Cutler et al. (1990). The authors recognized the different needs of people at different ages, such as people younger than 20 years old, which spend more for education than people in other age groups ( $\$ 2,553$ against $\$ 309$ in 1989 dollars), while people who are 65 and over spend more for health than those under 64 (\$5,360 against $\$ 1,262)$. In constructing the "support ratio," Cutler et al. (1990) constructed a needs-weighted consumption measure, where the number of people under 20 was adjusted by multiplying 0.72, while the number of people above 65 was multiplied by 1.27 . Weil (1999) also used these factors to incorporate the relative needs of the young and old in deducing the optimal fertility rate and population growth when pursuing consumption maximization. Prskawetz and Sambt (2014) extended the approach of Cutler et al. (1990) by differentiating the population into more age groups, and constructing and/or comparing the economic support ratios across the European countries using the National Transfer Accounts data.

Another line of analysis on the relationship between age and consumption is based on the life cycle theory that allows consumptions to vary across age. Kniesner, Viscusi, and Ziliak (2006) pointed out that if there is a life cycle plan to defer consumption until later age, the value of life of the elderly would be higher than that of the young. Erlandsen and Nymoen (2008) empirically documented that the age distribution of the population have significant and life cycle consistent effects on aggregate consumption by using the Norwegian quarterly time series data on aggregated level. Alessie and de Ree (2009) documented hump-shaped (log) household income, durable and nondurable consumption over the life (or age) profiles of Dutch households.

The exercise of "equivalent scale" popularized in poverty assessment shares similarities with our efforts to reflect the economic needs of people at different ages in the dependency ratio. The equivalent scale proposed by Deaton (1997) incorporates the household composition when measuring consumption per capita by including both the effect of "economies of scale" and "different needs of people at different age." Different from our framework, their focus is on a welfare measure reflected by the share of food consumption rather than absolute consumption expenditures; also, there is no role of productivity in their framework.

The previous literatures are mainly focused on age-specific consumption through the perspective of life cycle view and based on macro data. The household structures (coresidency style) on micro level are largely ignored. For example, elderly people who lived alone would consume much more differently than their peers who lived with their offspring. With changes in household structures, the consumption and dependency ratio will change accordingly.

To fill the void of current literatures, our paper contributes in two ways: (i) Different from Cutler et al. (1990), Weil (1999), and Prskawetz and Sambt (2014), we estimate the factor of relative needs of people at different ages based on a regression model. The household age compositions and size are embedded automatically. In the linear regression equation, the numbers of household members in different age groups are included as independent variables. We then transform the coefficient estimate of the number of household members in different age groups into the needs and/or contribution of 
people. The variation of regions within a country -in terms of productivity and/or living standards-is also embedded. (ii) Most of the works along this line are for developed countries such as the United States (US) and the European countries. Our analysis will use household survey data from five developing countries in Asia: Bangladesh, Cambodia, the People's Republic of China (PRC), Thailand, and Viet Nam. To our limited knowledge, this is a pioneer work in exploring patterns for such countries.

Building on our proposed methodology, we found the following: (i) The consumption- and productivity- adjusted dependency ratio (both total and old dependency ratios) were consistently lower than those that were traditionally defined across all five countries in our sample; and between countries, the differences between the consumption- and productivity-adjusted dependency ratio and those that were traditionally defined varied from country to country. (ii) For the PRC, the relatively younger elderly members of the population between 65 and 72 years helped reduce the consumption of young members in their households, while the elderly members who lived alone consumed more than their peers who lived with their offspring.

Section II sets up a linear regression model and deduces the equivalent needs of population members at different ages. Section III introduces the survey data for the five countries in our sample. Section IV reports the estimated factor of equivalent needs and the corresponding dependency ratios for the five sample countries. Section $V$ is dedicated to the PRC; it further explores the impacts of household co residence styles on household consumptions. Section VI simulates the time trends of the consumption- and productivity-adjusted dependency ratios, decomposes the consumption changes into income-induced and household structure-induced components, and discusses the implications of urbanization and that of smaller households driven by the one-child policy. Section VII concludes.

\section{CONSUMPTION-AND PRODUCTIVITY-ADJUSTED DEPENDENCY RATIO}

The traditional way of defining the total dependency ratio and the old dependency ratio is shown below: Total dependency ratio $=\frac{N_{\text {young }}+N_{\text {old }}}{N_{\text {middle }}}$, and Old dependency ratio $=\frac{N_{\text {old }}}{N_{\text {middle }}}$, where $N x$ indicates the number of people in age group $x$.

The numerator represents the consumption burden generated by the young and old people and the denominator presents the income-generating ability. An implied assumption is that the consumption per capita for young and old people is equivalent to the income per capita of people in the labor force, which ignore both the productivity evolvement of the labor force population and consumption variation across different household types. To incorporate the consumption and income and/or productivity, we suggest redefining the ratios as follows:

Consumption- and productivity-adjusted total dependency ratio $=\frac{C_{\text {young }} * N_{\text {young }}+C_{\text {old }} * N_{\text {old }}}{Y_{\text {middle }} * N_{\text {middle }}}$

where $C_{\text {young }}$ and $C_{\text {old }}$ are average consumption expenditure per young and old people respectively, and $Y_{\text {middle }}$ is the average income per labor force age people. The income is to represent the productivity of the labor force age member. Correspondingly, the expenditure- and income-adjusted old dependency ratio is defined as

$$
\text { Consumption- and productivity-adjusted old dependency ratio }=\frac{C_{\text {old }} * N_{\text {old }}}{Y_{\text {middle }}^{* N_{\text {middle }}}}
$$


To compute the consumption- and productivity-adjusted dependency ratio, we use a log-linear regression equation for both consumption and income. ${ }^{1}$

$$
\begin{aligned}
& \log C_{i}=\alpha+\sum_{v=1}^{3} \delta_{v} N_{i v}+\varepsilon_{i} \\
& \log Y_{i}=\theta+\sum_{v=1}^{3} \gamma_{v} N_{i v}+\epsilon_{i}
\end{aligned}
$$

where $C_{i}$ and $Y_{i}$ are the consumption expenditure and income, respectively, of household $i$; and $\varepsilon_{i}$ and $\in_{i}$ are i.i.d. error terms.

The explanatory variable in equations (3) and (4), $N_{i v}$, is the number of household members in each age group $v$ in household $i$. This idea originates from Mankiw and Weil (1989) who used this framework to evaluate the housing demand of household members in different age cohorts. In this paper, we use the framework to decompose the consumption expenditure and income contribution of household members at different stages. Following the common practice used by United Nations and The World Bank Group, we define three age groups $(v=3$ ), young (younger than 15 years old), labor force age (between 15 and 64 years old), and old (above 64 years old). For example, we have a household with one child, one middle-aged couple, and one old couple. Hence, $S_{i 1}=1, S_{i 2}=2$, and $S_{i 3}=2$. The coefficient parameter $\delta_{v}$ indicates the average consumption requirement of one member in age group $v$ and $\gamma_{v}$ represents the average income contribution of one member in age group $v$. The intercept terms represent the average level consumption and income across the sample.

The logarithmic transformation of household consumption and income as $\log C_{i}$ and $\log Y_{i}$ in equation (3) and (4) fulfills normal distribution assumption in the ordinary least squares.

To use the estimated coefficients to calculate equivalent population in consumption- and income-adjusted dependency ratio, we translate the coefficients of the number of family members in different age groups on logarithm transferred consumption and income into levels of consumption and income.

is,

We adopt first-order Taylor expansion to get $\hat{C}_{\text {old }}$ when $N_{\text {old }}=1$ starting from $N_{\text {old }}=0 .^{2}$ That

$$
\begin{gathered}
E E\left(\exp \left(\hat{\alpha}+\hat{\delta} N_{\text {old }}\right)\right) \\
=E(\exp (\hat{\alpha})+\exp (\hat{\alpha}) \hat{\delta})=\exp (\hat{\alpha})+\exp (\hat{\alpha}) \hat{\delta}_{\text {old }} \\
\text { with } N_{\text {old }}=0
\end{gathered}
$$

Applying the same logic to $C_{\text {Young }}$ and $Y_{\text {middle }}$, we have:

$$
\begin{aligned}
& E\left(C_{\text {Young }}\right)=\exp (\hat{\alpha})+\exp (\hat{\alpha}) \hat{\delta}_{\text {young }} \\
& E\left(Y_{\text {middle }}\right)=\exp (\hat{\theta})+\exp (\hat{\theta}) \hat{\gamma}_{\text {middle }}
\end{aligned}
$$

\footnotetext{
1 We take log-transformation because the distribution of original consumption is close to log-normal distribution. The comparisons of quantile-quantile (Q-Q) plots are included in the appendix figure.

2 First-order Taylor approximation when $x$ close to a value of $a$ defined as $f(x) \approx f(a)+f^{\prime}(a)(x-a)$, in p. 44 of Economists' Mathematical Manual. $N_{\text {old }}=a=0$ and $N_{\text {old }}=x=1$.
} 
After estimating $\alpha, \theta, \delta_{\text {old }}, \delta_{\text {young }}$, and $\gamma_{\text {middle }}$, we can employ equations (5) to (7) to calculate the average consumption per young and/or old member and the average income per member at labor force age, which will be used in equations (1) and (2) to get the income and consumption expenditureadjusted ratios.

\section{DATA}

We employ the household survey data from Bangladesh, Cambodia, the PRC, Thailand, and Viet Nam. We considered two factors in selecting these countries. First, the PRC is the focus country of our analysis. To serve the purpose of our analysis, we need both the data on expenditure and income. The most upto-date data with both income and expenditure information available is the China Household Finance Survey (CHFS) 2011. The other four economies are peer countries in emerging Asia with both income and expenditure in the household survey data. To be more comparable, we choose the survey conducted during the years close to 2011, which are the Household Income \& Expenditure Survey 2010 for Bangladesh, Cambodia Socio-Economic Survey 2009, Household Socio-Economic Survey 2009 for Thailand, and Household Living Standards Survey 2010 for Viet Nam. Questionnaires are included in the appendix.

The CHFS 2011 consists of 8,438 households and 29,463 individuals. The weighted average household size is 2.94 individuals -2.67 for urban households and 3.18 for rural households. ${ }^{3}$ In the survey, respondents were asked to provide information on their daily expenditures, durable goods and services expenditures, and financial assets allocations. Daily consumption includes expenditures on food, utility, daily-use products, housing services, local transport, telecommunication, and culture and entertainment activities. Durable goods and services consumption includes clothing, housing renovation and maintenance, heating, household durables, and education and training. Financial assets consist of demand deposits, time deposits, stocks, bonds, funds, derivatives, financial products, nonyuan-denominated assets, gold, and cash. The 2011 CHFS also gives information on individual household members, like age, gender, education, and occupation.

\section{EMPIRICAL ESTIMATIONS OF CONSUMPTION- AND PRODUCTIVITY-ADJUSTED DEPENDENCY RATIO}

To incorporate the geographic and municipal variations, we include dummy variables to represent the municipal provinces and/or central government directly controlled city and/or autonomous regions. For example, for the PRC, we have 25 provinces and/or central government directly controlled city/autonomous regions sampled. ${ }^{4}$ For each province, city, and region, we further divide them into urban and rural areas. Beijing, Qinghai, and Tianjin are the three cities and/or provinces having only urban area sample whereas Guangxi, Guizhou, and Shaanxi are the three provinces that have only rural area sample.

As planned, we run a regression with income and expenditure for each country in our sample. However, we found that there are significant proportions of households reporting higher expenditure than income. For example, for Bangladesh, 8,156 of the 11,210 households have higher expenditure than

3 More details of the survey can be found in http://www.chfsdata.org/detail-14,15.html.

4 They are Anhui, Beijing, Gansu, Guangdong, Guangxi, Guizhou, Hebei, Henan, Heilongjiang, Hubei, Hunan, Jilin, Jiangsu, Jiangxi, Liaoning, Qinghai, Shandong, Shanxi, Shaanxi, Shanghai, Sichuan, Tianjin, Yunnan, Zhejiang, and Chongqing. 
income; for Cambodia, 8,768 of the 11,348 households; for Thailand, 22,025 of the 43,530 households; for Viet Nam, 2,837 of the 9,395 households; and 854 of the 6,359 households for the PRC. ${ }^{5}$

Such phenomena may indicate a tendency of income underreporting across countries, which has been documented in previous literatures. Therefore, we use the coefficient of middle-aged member in the expenditure equation to replace the coefficient of middle-aged member in the income equation, under which we assume that the middle-aged member's productivity is measured in terms of consumption rather than income for the baseline case. As shown in Tables 1 and 2, the coefficient estimates for middle-aged members in the income equation (Table 2) are constantly higher than those in the expenditure equation (Table 1). It assures us that using the coefficients in the expenditure equation is a conservative approach to represent productivity. We also estimate the dependency ratios with the coefficient estimate for middle-aged member in income equation to represent productivity, which is provided as an alternative measure.

Table 1: Regression of Consumption on Household Age Components

\begin{tabular}{|c|c|c|c|c|c|}
\hline & Bangladesh & Cambodia & PRC & Thailand & Viet Nam \\
\hline Intercept $\boldsymbol{\alpha}_{\mathbf{1}}$ & $\begin{array}{c}8.314^{*} \\
(0.022)\end{array}$ & $\begin{array}{l}12.841^{*} \\
(0.024)\end{array}$ & $\begin{array}{c}9.139^{*} \\
(0.066)\end{array}$ & $\begin{array}{c}9.511^{*} \\
(0.014)\end{array}$ & $\begin{array}{l}14.838^{*} \\
(0.032)\end{array}$ \\
\hline No. of young $\left(\boldsymbol{\delta}_{\mathbf{1}}\right)$ & $\begin{array}{c}0.07^{*} \\
(0.004)\end{array}$ & $\begin{array}{r}0.075^{*} \\
(0.004)\end{array}$ & $\begin{array}{c}0.104^{*} \\
(0.013)\end{array}$ & $\begin{array}{r}0.047^{*} \\
(0.004)\end{array}$ & $\begin{array}{c}0.074^{*} \\
(0.006)\end{array}$ \\
\hline No. of middle aged $\left(\boldsymbol{\delta}_{\mathbf{2}}\right)$ & $\begin{array}{r}0.227^{*} \\
(0.004)\end{array}$ & $\begin{array}{c}0.159^{*} \\
(0.003)\end{array}$ & $\begin{array}{c}0.141^{*} \\
(0.008)\end{array}$ & $\begin{array}{r}0.229^{*} \\
(0.003)\end{array}$ & $\begin{array}{r}0.225^{*} \\
(0.005)\end{array}$ \\
\hline No. of old $\left(\boldsymbol{\delta}_{\mathbf{3}}\right)$ & $\begin{array}{c}0.115^{*} \\
(0.011)\end{array}$ & $\begin{array}{l}0.082^{*} \\
(0.01)\end{array}$ & $\begin{array}{l}-0.03^{*} \\
(0.017)\end{array}$ & $\begin{array}{c}0.014^{*} \\
(0.005)\end{array}$ & $\begin{array}{c}0.082^{*} \\
(0.011)\end{array}$ \\
\hline $\begin{array}{l}\text { Adjusted R-squared } \\
\text { No. of observations }\end{array}$ & $\begin{array}{l}0.2976 \\
11,200\end{array}$ & $\begin{array}{r}0.3455 \\
11,321\end{array}$ & $\begin{array}{r}0.2790 \\
6,359\end{array}$ & $\begin{array}{l}0.2490 \\
43,522\end{array}$ & $\begin{array}{r}0.2921 \\
9,329\end{array}$ \\
\hline
\end{tabular}

PRC $=$ People's Republic of China.

Note: ${ }^{*}$ denote significance at the $10 \%$ level.

Source: Authors.

Table 2: Regression of Income on Household Age Components

\begin{tabular}{l|ccccc}
\hline & Bangladesh & Cambodia & PRC & Thailand & Viet Nam \\
\hline Intercept $\boldsymbol{\theta}_{\mathbf{1}}$ & $7.171^{*}$ & $12.132^{*}$ & $8.702^{*}$ & $9.566^{*}$ & $14.727^{*}$ \\
& $(0.063)$ & $(0.049)$ & $(0.118)$ & $(0.028)$ & $(0.04)$ \\
No. of young $\left(\boldsymbol{\gamma}_{\mathbf{1}}\right)$ & $-0.022^{*}$ & $0.068^{*}$ & $0.069^{*}$ & $0.034^{*}$ & $0.11^{*}$ \\
& $(0.012)$ & $(0.008)$ & $(0.023)$ & $(0.007)$ & $(0.007)$ \\
No. of middle aged $\left(\boldsymbol{\gamma}_{\mathbf{2}}\right)$ & $0.327^{*}$ & $0.191^{*}$ & $0.234^{*}$ & $0.242^{*}$ & $0.28^{*}$ \\
& $(0.011)$ & $(0.007)$ & $(0.015)$ & $(0.005)$ & $(0.006)$ \\
No. of old $\left(\boldsymbol{\gamma}_{\mathbf{3}}\right)$ & $0.182^{*}$ & -0.007 & $-0.392^{*}$ & $0.034^{*}$ & 0.01 \\
\multicolumn{7}{l}{ Adjusted R-squared } & $(0.031)$ & $(0.021)$ & $(0.03)$ & $(0.01)$ & $(0.014)$ \\
No. of observations & 0.097 & 0.193 & 0.2107 & 0.1045 & 0.2942 \\
\multicolumn{2}{l}{ Condensed dummy variables for regions } \\
\hline
\end{tabular}

PRC = People's Republic of China.

Note: * denote significance at the $10 \%$ level.

Source: Authors.

5 For the PRC, after restraining the data to have income and expenditure data available, the number of observations was reduced to 6,359. 
In Table 1, we report the intercept term and coefficient estimates in consumption expenditure equation (3). All the region dummies are condensed in the table to help in emphasizing the main focus of this study. The intercept term, therefore, can be regarded as the benchmark region. Table 1 shows that (i) by including only the age compositions of the household members and the geographic dummies, the household consumption variations are explained in a quite significant portion. The adjusted Rsquared varies from 0.25 (Thailand) to 0.35 (Cambodia); (ii) members of different age groups consume very differently-in each country, the household members who are middle-aged have the highest coefficient. In some countries, the old members consume more compared to young members (e.g., Bangladesh) while in other countries, the young members consume much more than the old members (e.g., the PRC and Thailand).

The PRC has a significant negative estimate for elderly members. That is, on average, one additional member at old age can reduce the household consumption in the PRC. We are going to explore these interesting facts by controlling household income and provide explanations in section $\mathrm{V}$.

Table 2 presents the estimation results for income regression in equation (4). For each country, the explaining power of household age composition for income is much lower than that for consumption, except for Viet Nam. As expected, household member at labor force age is the main source of income. One interesting result is the significant positive coefficient for young members in Cambodia, the PRC, Thailand, and Viet Nam. Since we group members under 15 years old as young members and there are no households with only young members, the positive coefficient may signal middle-aged members in households with young members might spend more effort in their work and generate higher income than their peer without young children. We test this hypothesis by adding one new variable into the income regression. The new variable is constructed by multiplying a dummy variable (equal to 1 if the household has young members) with the number of middle-aged members. The results are presented in the appendix table. After including this new variable, the coefficient of the number of young member turns out to be insignificant for the PRC. However, the coefficients of Cambodia, Thailand, and Viet Nam are still positively significant. Therefore, the hypothesis of a higher income of households with young members through the hard work of middle-aged parents only holds true for the PRC.

Similar to the results listed for the consumption in Table 1, the elderly members in the PRC turn out to have significant negative contributions to the household. It may imply that the elderly members living separately with their children earn much less than their peers who live together with their offspring. We examine this hypothesis by including an additional variable-by multiplying a dummy indicating the elderly member living with their children with the number of elderly members. As shown in the appendix table, those who live together enjoy a significant positive income compared with their peers living in other types of households. Surprisingly, such effects hold true for all the five countries included. The heterogeneity revealed by the appendix table across countries are very interesting, however, to focus on the consumption side, we leave this topic for further research.

Substituting the coefficient estimates in Table 1 and Table 2 into equations (5) to (7), we estimate the average consumption per young and/or elderly member and the average income per member at labor force age, as presented in Table 3.

Using the estimates in Table 3 and the number of people in each age group in the sampled data, we calculate the old dependency ratio and total dependency ratio with the consumption and productivity adjusted and with the traditional approach. The results are presented in Table 4 . The first two columns of Table 4 listed the old dependency ratio and the total dependency ratio using the consumption- and productivity-adjusted method, and the following two columns listed the two ratios 
under traditional method. With the traditional method, the old dependency ratio and total dependency ratio are higher than those with the consumption and productivity adjusted for all the five countries in our sample. Thailand has the largest difference between the old dependency ratio and the traditional one, 0.028 higher than the adjusted one, while Cambodia has the smallest difference. Bangladesh has the largest difference in the total dependency ratio between these two methods at 0.08 while the PRC has the smallest difference at 0.02 .

Table 3: Estimated Consumption and/or Income Equivalent Unit

\begin{tabular}{lrrr}
\hline & \multicolumn{1}{c}{$\boldsymbol{C}_{\text {old }}$} & \multicolumn{1}{c}{$\boldsymbol{C}_{\text {Young }}$} & \multicolumn{1}{c}{$\boldsymbol{Y}_{\text {Middle }}$} \\
\hline PRC & $13,027.70$ & $14,830.36$ & $15,331.30$ \\
Cambodia & $462,383.50$ & $459,805.30$ & $495,434.80$ \\
Bangladesh & $4,731.14$ & $4,541.58$ & $5,204.04$ \\
Thailand & $8,437.79$ & $8,713.13$ & $10,227.51$ \\
Viet Nam & $1,778,888$ & $1,766,395$ & $2,013,815$ \\
\hline
\end{tabular}

PRC = People's Republic of China.

Notes: The amounts are in domestic currencies of each country. ${ }^{*}$ denote significance at the $10 \%$ level. Source: Authors.

Table 4: Comparison of Dependency Ratios with Sampled Data

\begin{tabular}{l|cc|cc}
\hline & \multicolumn{2}{|c|}{$\begin{array}{c}\text { Method } \\
\text { Mensumption- and Productivity-Adjusted }\end{array}$} & \multicolumn{2}{c}{ Traditional Method } \\
\hline & $\begin{array}{c}\text { Old Dependency } \\
\text { Ratio }\end{array}$ & $\begin{array}{c}\text { Total Dependency } \\
\text { Ratio }\end{array}$ & $\begin{array}{c}\text { Old Dependency } \\
\text { Ratio }\end{array}$ & $\begin{array}{c}\text { Total Dependency } \\
\text { Ratio }\end{array}$ \\
\hline PRC & 0.097 & 0.320 & 0.114 & 0.345 \\
Cambodia & 0.065 & 0.536 & 0.070 & 0.578 \\
Bangladesh & 0.076 & 0.569 & 0.084 & 0.649 \\
Thailand & 0.133 & 0.401 & 0.161 & 0.476 \\
Viet Nam & 0.090 & 0.406 & 0.101 & 0.462 \\
\hline
\end{tabular}

PRC = People's Republic of China.

Source: Authors.

We further check the robustness of the estimations. We replace the logarithm transformed household consumption and income with the original household consumption and income directly as the left-hand-side variables as in equations (3) and (4). The adjusted old dependency ratio is now calculated as 0.075 and the total dependency ratio is 0.287 , which are very close to the adjusted ratios with the logarithm transformed consumption and income presented in Table 4. The reason we do not use the consumption and income as the left-hand-side variable directly as the baseline model is because they are obviously not normally distributed, which hinder the employment of ordinary least squares. The similarly calculated adjusted ratios assure us of the robustness of the estimations.

\section{HOUSEHOLD CONSUMPTIONS AND CORESIDENCE STYLE IN THE PEOPLE'S REPUBLIC OF CHINA}

The PRC has been experiencing rapid economic growth and continues to exert increasing influence on the rest of the world. The average annual growth rate of gross domestic product (GDP) reached 9.9\% between 1979 and 2010 and its GDP per capita rose to around \$8,000 in 2015 from $\$ 54$ in 1952 and $\$ 229$ in 1978. The PRC's extraordinary economic boom accompanied the expansion of urbanization. In 1950, only 13\% of people in the PRC lived in urban areas. By 2010, the urban share of the population 
grew to $45 \%$. Household structure has also changed due to increasing urbanization. Household size shrank as more people moved to urban areas, more females joined the professional work force, and the unique "one-child policy" was implemented in 1979. The intrahousehold dynamics of consumptionrelated decision making also evolved. The impact of household structure on household consumption in the PRC has implications not just in the PRC but also to the rest of the world.

One main driver of household consumption growth comes from growth in productivity, reflected by the household income. We examine whether such positive correlation exists. To control for the effect of household size, we divide the households into different groups: households with only one member, households with two members, and households with three members. Within each group, we plot the logarithm transformed income as the horizontal axis and the corresponding expenditure as the vertical axis. As shown in Figure 1, there are clear positive correlations between income and consumption within each size group. The dashed line is a 45 -degree line. The solid line is the fitted line using a linear regression. The slope of the solid line is smaller than that of the dashed line, which implies, as expected, that the elasticity of consumption to income is lower than 1. That is, with one-unit increase in income, only part of it will be spent.

Figure 1: Relations between Household Consumption and Income Conditional on Household Size
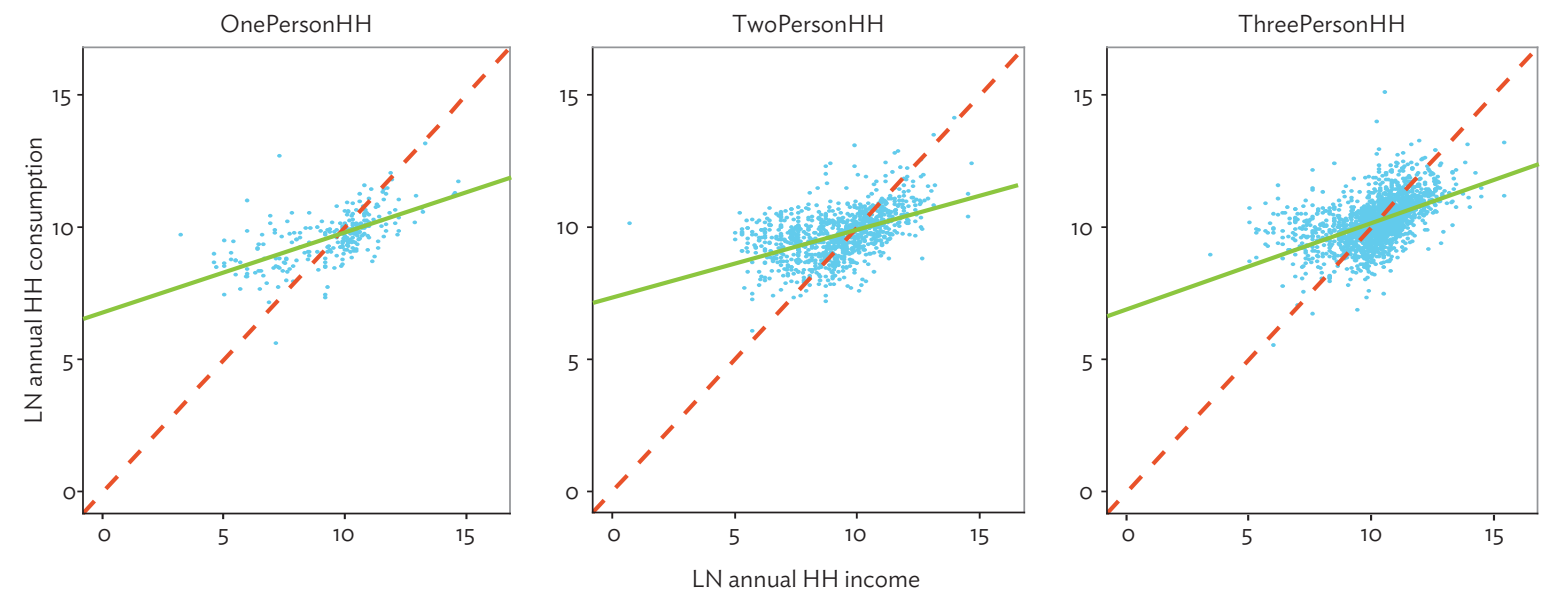

$\mathrm{HH}=$ household, $\mathrm{LN}=$ natural logarithm transformation.

Source: Authors.

The next question is, whether members of different age groups, within the same household size group, consume differently, which is similar to the idea discussed in constructing the dependency ratio. For example, in a household with three members, we want to know whether the household consumption of two adults and one child differs from that of a household with two adults and one elderly member. That is, whether the style of coresidence matters for household consumptions, which will induce different aggregated consumption for the whole society. In Figure 2, we give the Box-and-Whiskers plotting of household consumptions for three household sizes: single-person households, two-member households, and three-member households. ${ }^{6}$ Within each size group, we further differentiate the household age structures. In Figure 2, the top panel includes two household age structures for the single-

6 The bold bar in the middle indicates median value and the upper/lower border lines for the box indicate values at $25 \%$ and 75\% (quartile 1 and quartile 3 ). The far-end bars are maximum and minimum values. 
member household: the middle-aged single-member households and the elderly single-member households. The median consumption of households with an elderly member is much lower than that with a middle-aged member. The middle panel shows heterogeneities in the consumptions of households with two members. While they all have two members, the households with one middle-aged and one young member or with two middle-aged members have the highest median consumptions while the households with one elderly member and one young member have the lowest median consumption. The fact that the median consumption of households with two middle-aged members is not different from those with one middle aged and one young member implies that such difference in consumption cannot be justified by the higher earning ability associated with more middle-aged members. The bottom panel shows variations across different age compositions for households with three members. The households with young members tend to have higher consumptions while the ones with elderly members tend to have lower consumptions.

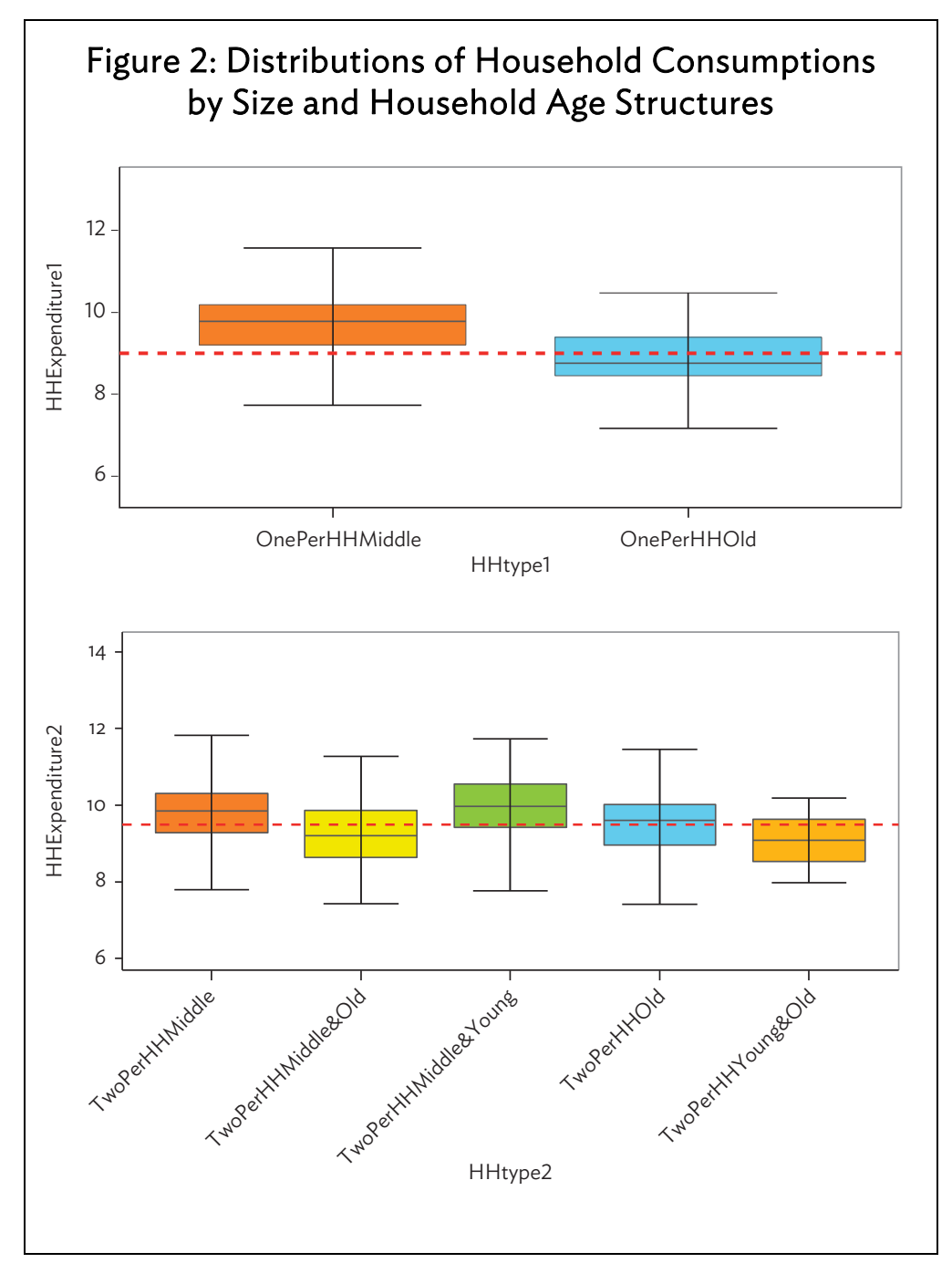

continued on next page 


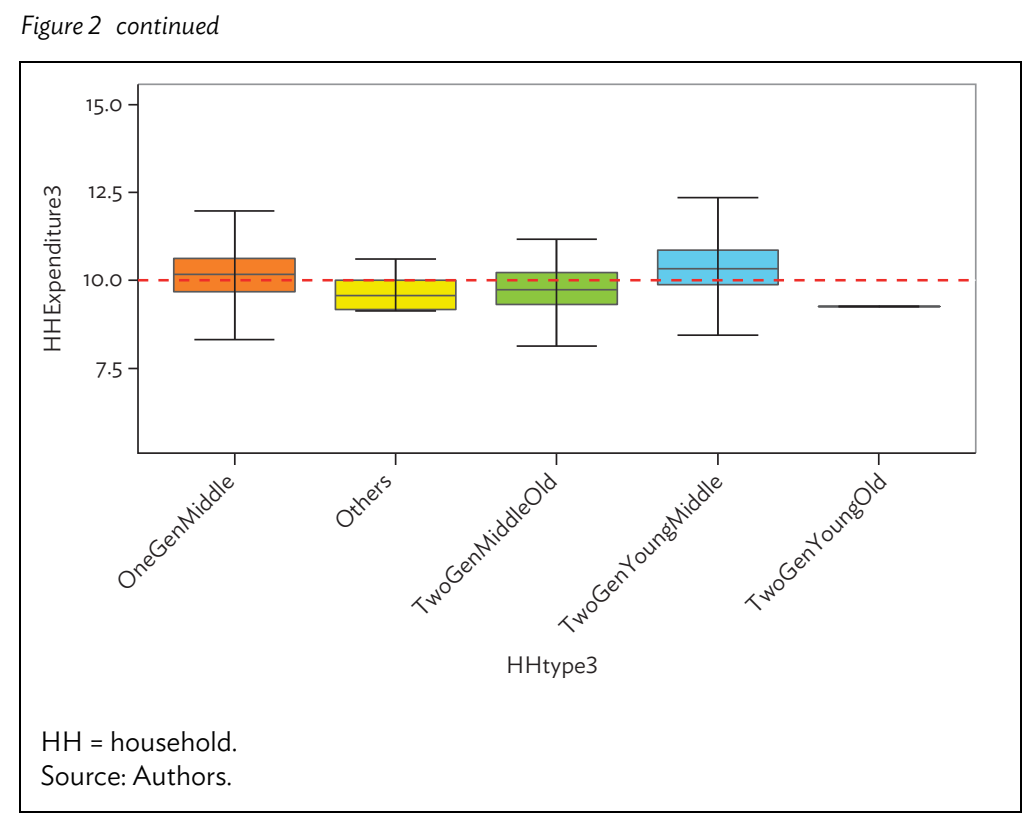

Comparing the consumption levels across different sizes, we find that larger households do not necessarily consume more. As shown in Figure 2, the dashed lines for all three panels indicate the same consumption level. We do have some households, which are above the line and some are below the line for both two-member and three-member households. Households with three members, with no young member, consume less than households with only two members, with one middle aged and one young member.

To explore the interesting pattern in a more scientific way, we formulate the issue with regressions. Different from regression (3) in calculating the dependency ratio, we introduce the household income as a control variable. The regional dummies are still included to represent the differences in consumption and/or living standards across provinces and rural and/or urban area. Then we have equation (8):

$$
\log C_{i}=\alpha_{r}+\beta \log Y_{i}+\sum_{v=1}^{3} \delta_{v} N_{i v}+\varepsilon_{i}
$$

where $\log C_{i}$ and $\log Y_{i}$ are logarithm transformed annual consumption and income of household $i$, respectively. $N_{i 1}, N_{i 2}$, and $N_{i 3}$ are the numbers of household members at young, middle, elderly age, respectively. $\alpha_{r}$ is a dummy variable indicating which province household $i$ belongs to. Within each province, we further divide the location into rural and urban. Twenty-five provinces and/or cities were sampled in the CHFS 2011. We further differentiate urban area and rural area for each province. At the end, we have 44 regions. ${ }^{7}$ That is, in addition to the intercept, we have 43 dummies for the regions.

In the framework of the classic Keynesian theory with life cycle hypothesis and the permanent income hypothesis, the consumption function includes expectations of future income, wealth, real interest rate, and others. Different from the classic Keynesian framework, we include only the current household disposable income and the age structure of household members and their coresidence styles for two reasons: (i) Rather than forecasting the future consumptions, our goal is to measure the relative

7 These are rural and urban areas of 25 provinces and/or cities excluding those three provinces without rural data sampled, and three provinces without urban data sampled. 
consumption needs across members at different ages and assess all households at the same time point. All the variables related with expectations or of having time-varying nature, such as expectations of future income and real interest rate, will have the exact same impact on all households analyzed. Therefore, excluding those variables in the regression does not induce "missing-variable" bias. (ii) We include regional dummy in our regression, which approximates the wealth in consumption function. We are not the first one to attempt using this simplified consumption function. For example, Mankiw and Weil (1989) and Han (2010) have used similar simple household age decomposition in analyzing housing demand.

We further extend the specification by differentiating two types of coresidences: one is a threegeneration household with an elderly member between 65 and 72 years old, and the others are elderly members who live separately with their offspring. ${ }^{8}$ We formulate it as the following equation (9):

$$
\log C_{i}=\alpha_{r}+\beta \log Y_{i}+\left(\delta_{1}+\delta_{1}^{D} D_{1}\right) N_{i 1}+\delta_{2} N_{i 2}+\left(\delta_{3}+\delta_{3}^{D} D_{3}\right) N_{i 3}+\varepsilon_{i}
$$

where $D_{1}=1$, if the household is a three-generation household with the elderly member between age 65 and 72, 0 otherwise; and $D_{3}=1$, if the old members live alone, 0 otherwise.

A three-generation household means there is at least one member in each age group in the household. We expect to have a negative estimate of $\delta_{1}^{D}$. That is, a relatively young elderly member who is between 65 and 72 years old in a three-generation household can help take care of the young generation and reduce the consumptions of the young member compared with young members living in a different type of household, such as a two-generation household. On the contrary, old members who live in a household without younger members would consume more after controlling the income, compared to their peers living in other types of households, reflected by a negative estimate of $\delta_{3}^{D}$, which also implies scale of economy.

In Table 5, column (1) presents the results for the baseline model, in which the elasticity of household consumption to income is 0.186 . That is, with a $1 \%$ increase in household income, there is a $0.186 \%$ increase in consumption. All three coefficients for the young/middle aged/elderly members are significantly positive after controlling household income, which is different from the results listed in Table 3.

In column (2), we estimate the specification of equation (9). As we expected, the consumption of young members who live in a three-generation household with a relatively young elderly member (between 65 and 72 years old) is much lower than their counterparts in other types of households, around two-thirds less $(0.099-0.067=0.032)$. We also do robustness check by applying a dummy variable to middle-aged members, which turns out to be of no significant impact.

The other estimate for elderly members who live separately with their offspring $\delta_{3}^{D}, 0.07$ as shown in column (3) in Table 5 , is significantly positive. That is, their peers living together with an offspring consume 0.029 while they consume $0.099(0.07+0.029)$.

8 We have tried age-breaking point for the younger elderly people from 70 to 75 . The one that uses 72 gives the most significant effect and has the highest explanatory power. Therefore, we choose 65-72 years old as the range for younger elderly member. 
Table 5: Household Consumptions and Coresidence Styles

\begin{tabular}{|c|c|c|c|}
\hline & $(1)$ & $(2)$ & (3) \\
\hline Intercept $\boldsymbol{\alpha}_{\mathbf{1}}$ & $\begin{array}{l}7.52^{*} \\
(0084)\end{array}$ & $\begin{array}{l}7.509^{*} \\
(0085)\end{array}$ & $\begin{array}{l}7.479^{*} \\
(0.087)\end{array}$ \\
\hline Coefficient of $(\boldsymbol{\beta})$ & $\begin{array}{l}0.186^{*} \\
(0.007)\end{array}$ & $\begin{array}{l}0.187^{*} \\
(0.007)\end{array}$ & $\begin{array}{l}0.189^{*} \\
(0.007)\end{array}$ \\
\hline No. of young $\left(\boldsymbol{\delta}_{\mathbf{1}}\right)$ & $\begin{array}{l}0.091^{*} \\
(0.012)\end{array}$ & $\begin{array}{l}0.099^{*} \\
(0.013)\end{array}$ & $\begin{array}{l}0.093^{*} \\
(0.012)\end{array}$ \\
\hline No. of middle aged $\left(\boldsymbol{\delta}_{2}\right)$ & $\begin{array}{l}0.098^{*} \\
(0.008)\end{array}$ & $\begin{array}{l}0.098^{*} \\
(0.008)\end{array}$ & $\begin{array}{l}0.102^{*} \\
(0.008)\end{array}$ \\
\hline No. of old $\left(\boldsymbol{\delta}_{\mathbf{3}}\right)$ & $\begin{array}{l}0.043^{*} \\
(0.016)\end{array}$ & $\begin{array}{l}0.057^{*} \\
(0.017)\end{array}$ & $\begin{array}{l}0.029^{*} \\
(0.017)\end{array}$ \\
\hline $\begin{array}{l}\text { Dummy for young member in } 3 \text {-generation households } \\
\left(\boldsymbol{\delta}_{1}^{\boldsymbol{D}}\right) \text { with younger elderly member }([65,72])\end{array}$ & & $\begin{array}{l}-0.067^{*} \\
(0.033)\end{array}$ & \\
\hline Dummy for elderly members living alone $\left(\boldsymbol{\delta}_{3}^{\boldsymbol{D}}\right)$ & & & $\begin{array}{c}0.07^{*} \\
(0.035)\end{array}$ \\
\hline $\begin{array}{l}\text { Adjusted R-squared } \\
\text { No. of observations }\end{array}$ & $\begin{array}{r}0.36 \\
6,359\end{array}$ & $\begin{array}{r}0.36 \\
6,359\end{array}$ & $\begin{array}{r}0.36 \\
6,359 \\
\end{array}$ \\
\hline Condensed dummy variables for regions & & & \\
\hline
\end{tabular}

\section{CONSUMPTION SIMULATIONS IN THE PEOPLE'S REPUBLIC OF CHINA}

\section{A. Time Trend of Traditional and Adjusted Dependency Ratios}

In this session, we simulate time trends for the adjusted total and old dependency ratios from 2000 to 2030 by assuming that the age-specific consumption and income pattern implied in the household survey data did not change within this time span. Both the historical and projected population numbers in different age groups are obtained from the United Nations' World Population Prospects data set. As shown in Figure 3, both the adjusted total dependency ratio and adjusted old dependency ratio are constantly lower than their traditional counterparts. One interesting trend is that the gaps between the adjusted and the traditional dependency ratios grow larger for more distant future, which shows that by taking into account the productivity-generating ability of the labor force population and the different consumption needs of population at different ages, the burden gets less heavier than the scenarios measured by the traditional measures, especially for the more distant future. For example, the traditional old dependency ratio is 0.11 for 2010 and 0.25 for 2030, whereas the adjusted counterpart is 0.09 for 2010 and 0.21 for 2030 . The traditional measure is 0.02 higher than the adjusted one for 2010, but 0.04 higher for 2030.

We are fully aware that there may be bias in such trend simulation because of strictly implied assumptions. For example, we assume that (i) relative consumption needs across different age groups do not change; (ii) urbanization does not change the age distribution of population; and (iii) there is no change in coresidence styles, etc. When the aforementioned assumptions do not bias all the trends toward one direction, that is, they generate both positive and negative biases, the average trends simulated still can reveal useful information. 


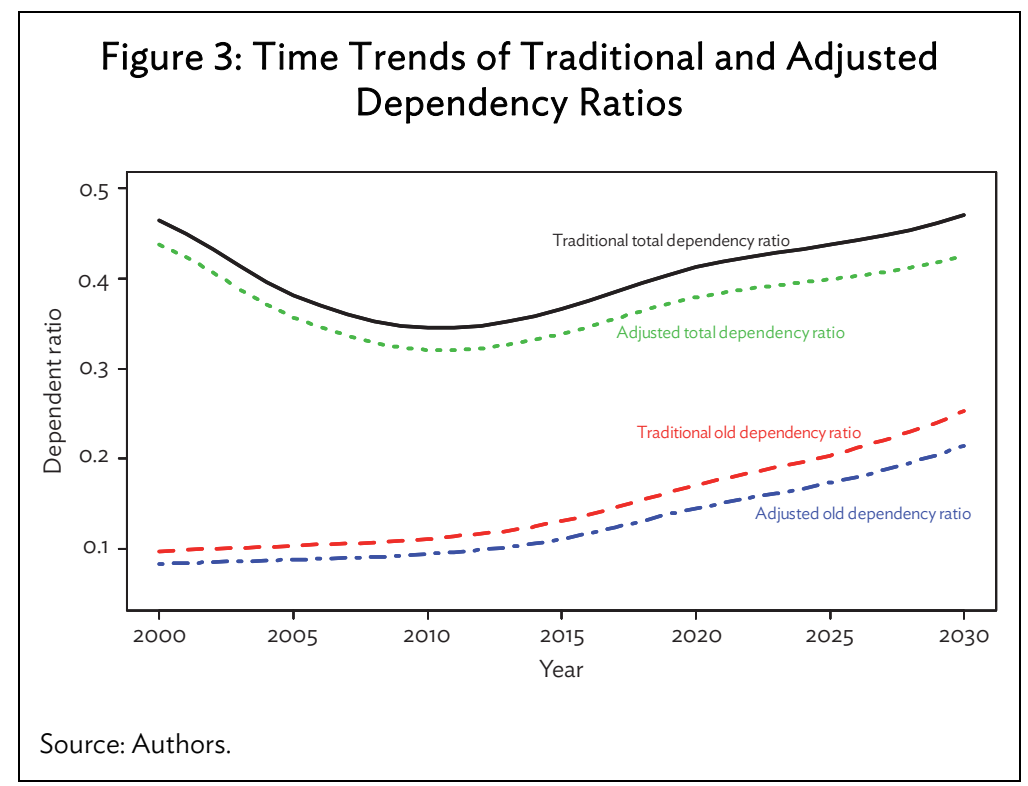

\section{B. What is the Impact on Household Consumption when Households Become Smaller?}

We arbitrarily separate any household with both middle-aged member and elderly members into two separate households: one with middle-aged members and the other with elderly members. The young member will be with the middle-aged members to form the simulated households.

Of the 6,539 households, there are 1,072 households with both at least one middle-aged member and one elderly member. To "filter" the effect of household size from other effects, we assume all households' income taking the value of the sample mean. Based on estimates in model specification presented in column (1) of Table 5 without differentiating the coresidence style, the aggregated household consumption of the whole society will increase by $16.26 \%$ on average.

However, as presented in column (3) of Table 5, whether the elderly members live with their offsprings or not matters to their consumption. We note that the consumption of elderly members who do not live with their offspring is significantly higher than their counterparts who live together with their offspring. That is, for an elderly member living with their offspring, their marginal contribution to the household consumption is 0.029 whereas the marginal contribution is $0.099(0.029+0.07)$ if they live on their own. Taking this coresidence style in consideration of the above-simulated scenario, the aggregated household consumption of the whole society would be $16.3 \%$ higher.

When household size becomes smaller, the aggregate consumption increases dramatically. Taking the PRC in 2015 as an example, the share of a household final consumption in GDP is around 58\% (World Bank 2017a), and 16.26\% increase in household final consumption is equivalent to 9.4\% of GDP, which should alarm the policy makers in making welfare-related policies.

In percentage, the difference of $0.04 \%(16.3 \%-16.26 \%)$ associated with coresidence style seems trivial. However, when we interpret it into level number, it is quite significant. The household final consumption of the PRC in 2015 is $\$ 4.25$ trillion in current US dollar (World Bank 2017b). The 0.04\% difference associated with the coresidence style is equivalent to $\$ 1.7$ billion difference in consumption, which is bigger than the whole economy of Bhutan ( $\$ 1.14$ billion in 2015) or the Central African Republic ( $\$ 1.59$ billion in 2015). 


\section{What is the Impact on Household Consumption of Immigration from Rural to Urban Areas?}

Taking advantage of the fixed effect dummy for rural and urban areas for each province in our modeling framework, we can simulate an artificial extreme scenario by moving all the households located in rural areas to the urban areas within the same province with the household income, household size, and age component untouched. That is, only the interprovince urbanization is assumed. The aggregated household consumption would be $1.48 \%$ higher. Multiplying it with the household final consumption of $\$ 4.25$ trillion, it will be equivalent to $\$ 6.3$ billion, which is the size of the economy of Ecuador $(\$ 6.2$ billion in 2015) or Hungary ( $\$ 6$ billion in 2015).

\section{What is the Impact of Economic Growth that is Associated to Aging on Household Consumption?}

Table 5 has shown that the elasticity of household consumption to income is around 0.19 across all three model specifications. That is, with unchanged household size and age structure, a $1 \%$ increase in household income will generate a $0.19 \%$ increase in consumption. If the population structure and coresidence style do not change, economic growth will alleviate the economic burdens in terms of dependency ratio. However, as we can expect, the economic growth will be accompanied with population aging, household downsizing, and urbanization, which will be associated with less income or more consumption.

As shown in Table 2, conditional on current household structure, one elderly member does not bring any income. On the contrary, the elderly member will significantly drag down the household's average income by -0.392 significantly. It may reflect the fact that the average wage rate of younger people is higher than that of elderly people, which has been observed in advanced economies, such as in the US, mainly due to the fact that the younger generation has more skills and are able to work in sectors with higher productivity. We take a numeric exercise and suppose one middle-aged member enters elderly stage. The household income will experience a $0.626(-0.392-0.234)$ reduction in income based on Table 2, which would then induce a $0.12\left(0.186^{*} 0.626\right)$ decrease in consumption through the income channels, and 0.073 (0.102-0.029) reduction in consumption through the aging channel if still living in the household, and almost no reduction in household consumption if the elderly member lives in a separate household. The speed of decrease in income is around 5 times the decrease in consumption, which implies that population aging may induce a much faster deterioration of dependency ratio than the numbers tell.

\section{CONCLUSION}

Population aging is now becoming a new norm for almost all emerging economies. The new norm brings paramount challenges. To accommodate this new norm, a comprehensive reform is urgently needed, especially in the PRC. A more scientific version of the dependency ratio is necessary for guiding the policy evolution.

According to our model, the consumption- and productivity-adjusted old dependency ratio in the PRC has at least 15 years lag when compared with the traditional dependency ratio. Based on our model, the old dependency ratio for 2011 is equal to the official statistics reading for 2000 . If such lag is a window for policy makers, we are willing to push the policy makers to harvest this window to better prepare the reform. 
The increase of consumption burden from elderly people has been driven by population aging as well as economic growth. With almost $7 \%$ annual income increase during the last 30 years, the total consumption from elderly people would increase at 1.5\% annually keeping population aging constant. This finding is helpful for designing the replacement rate in pension system. ${ }^{9}$ According to our model, indicated by the smaller coefficients (consumption needs) of the elderly people than those of the middle-aged people, a decreasing replacement rate is not necessarily harmful for elderly people's welfare but, on the contrary, is necessary for the sustainability of the pension system.

Chinese traditional culture cherishes the multigenerational households. This cherished culture is still intact, at least from the cultural perspective, but is slowly losing its attractiveness or is becoming more and more difficult to sustain in the era of urbanization and globalization. Household size continues to decline and nuclearization is clearly happening in the PRC. However, multigenerational households would be more attractive from a consumption. Given that the majority of the elderly people in the PRC still live with their adult children and we do foresee cultural continuity, we argue that the window until we lose the population dividend will be wider than anticipated given that the tradition of coresidence remains strong in the PRC.

Keeping a small household is probably the equivalent to a rational choice for family members, but is bad from an ecological perspective as it translates to inefficient energy use and land use consumption. It also translates to an inefficient manner of operating a low-cost household in terms of taking care of young members and/or taking care of older people. The old and total dependency ratio will significantly decrease if more and more people can choose living in the multigenerational household. Multigenerational household will be attractive and operable if some regulation constraints could be lifted. For example, in the PRC, an urgently needed nationalized pension system should promote the practice of elderly people moving in with their children that will result in a multigenerational household.

9 A replacement rate is the percentage of a worker's preretirement income that is paid out by a pension program upon retirement. 


\section{Appendix: On Estimating Household Income and Expenditure Using CHFS 2011 Data}

This documentation summarizes how household income and expenditure are estimated using the China Household Finance Survey (CHFS) 2011 data. Please note that we differentiate the variables itemized in the questionnaire and the variables included in the CHFS data set.

The income used in the analysis refers to the aggregated household after-tax income, which includes the sum of individual income (wages) and income tagged to the whole household.

The household consumption includes two main parts: annual expenditure on durable goods and monthly expenditure on nondurable goods. The monthly expenditures were adjusted to annual basis by multiplying with 12 .

\section{Income}

\section{a. Individual income}

Individual income can be differentiated into two types: after-tax income and gross income (income with tax).

After-tax income is the sum of after-tax wages from the primary job (a3020), after-tax bonuses (a3022), after-tax income-whether in-cash or in-kind-received from work (a3023), and after-tax income from the second job (a3036). ${ }^{10}$ In case the respondent is not willing to divulge his/her actual income, one has the option to specify which range the income falls: a3020it for after-tax wages from the primary job, and a3022it for after-tax bonuses. In the data set, total after-tax income is expressed in the variable individual labor income (labor_inc). The labor_inc variables do not only include actual after-tax income but also imputed after-tax income. Imputed after-tax income refers to the estimated income of respondents who do not want to divulge their actual income.

Gross income (or income with tax) is the sum of individual labor income (labor_inc), personal income taxes paid on the primary job (a3024), and personal income taxes paid on the second job (a3037).

\section{b. Income tagged to the whole household}

After-tax income tagged to the whole household is the sum of the following components:

After-tax income from agricultural activities is gross income from agricultural activities (b1005) less total cost of agricultural activities (b1012). Respondents who are not willing to disclose the actual amount can choose the range of these values instead in b1005it and b1012it, respectively. In the data set, we use the b1005_imp and b1012_imp variables to compute after-tax income because these variables include both actual and imputed values.

Profit income from production or operation of any industrial or commercial products is the net profit of projects (b2003c). In case the single projects and net profit data is not available, we get the profit of the project (b2015). If the respondent is not willing to disclose the actual amount, he/she has the option to choose from a range of values (b2015it). If the profit data of the project is still not available, we get the revenue or gross income of the project (b2014). If the respondent is not willing to

10 After-tax wage is pure wage income, that is, bonus, allowances, and others are not included. 
disclose the actual value, he/she has the option to choose from a range of values (b2014it). For the latter two items, actual and imputed values are combined to form a single variable-b2015_imp and b2014_imp, respectively.

\section{After-tax income from time deposits (d2106).}

After-tax income from stocks (d3117). If the respondent is unwilling to disclose the actual amount, he/she has the option to choose from a range of values (d3117it). In the data set, we have a single variable combining the actual and imputed values from the range (d3117_imp).

After-tax funds income (d5109). If the respondent is unwilling to disclose the actual amount, he/she has the option to choose from a range of values (d5109it). In the data set, we have a single variable combining the actual and imputed values from the range (d5109_imp).

After-tax income from derivatives (d6116). If the respondent is unwilling to disclose the actual amount, he/she has the option to choose from a range of values (d6116it). In the data set, we have a single variable combining the actual and imputed values from the range (d6116_imp).

After-tax income from financial products (d7112). If the respondent is unwilling to disclose the actual amount, he/she has the option to choose from a range of values ( $d 7112 i t$ ). In the data set, we have a single variable combining the actual and imputed values from the range (d7112_imp).

After-tax income from nonyuan-denominated assets (d8106). If the respondent is unwilling to disclose the actual amount, he/she has the option to choose from a range of values (d8106it). In the data set, we have a single variable combining the actual and imputed values from the range (d8106_imp).

After-tax income received from gold (d9105). If the respondent is unwilling to disclose the actual amount, he/she has the option to choose from a range of values ( $d 9105 i t)$. In the data set, we have a single variable combining the actual and imputed values from the range (d9105_imp).

Interest income from loans (k2108).

c. Additional notes: Zero and negative household income is replaced with "NA." Nine individuals reported personal income taxes but did not report their after-tax income.

\section{Expenditure (Annual, durable)}

Household expenditure is the sum of the expenses on the following items:

a. Clothing, which is the sum of the respondent's expenses on clothing (g1011), his/her spouse's expenses on clothing (g1011a), and their children's expenses on clothing (g1011b).

b. Housing renovation, maintenance, or expansion, which is the amount of expenses in the survey ( $(1012)$ divided by 5 , assuming 5 years of depreciation.

c. Heating (g1013).

d. Household durables, which is the amount of expenses in the survey (g1014) divided by 5 , assuming 5 years of depreciation. If the respondent is not willing to disclose the actual amount, 
he/she has the option to choose from a range of values (g1014it). In the data set, there is a single variable that combines both actual and imputed values (g1014_imp).

\section{e. $\quad$ Education and training (g1016).}

f. Conveyance ( $(1017)$. We multiply g1017 by 10,000 to get the value in yuan.

g. Travel (g1018). If the respondent is not willing to disclose the actual amount, he/she has the option to choose from a range of values (g1018it). In the data set, there is a single variable that combines both actual and imputed values (g1018_imp).

h. Health (g1019).

- $\quad$ Additional note: We compute total household expenditure as the sum of all items above and also total household expenditure without travel and health.

\section{Expenditure (Monthly, nondurable)}

The data set also contains monthly expenditure data on the following items (all in yuan):

a. Food, which is the expenditure on meals, including meals eaten outside of the home (g1001).

b. Agricultural production and market sale, which is the amount of money that agricultural products bring (g1004).

c. Utilities, which is the expenditure on water, electricity, fuel fees, property management, and maintenance (g1005).

d. Daily-use products, excluding food and clothing, which include detergent, soap, toothpaste, toothbrush, and other toiletries (g1006).

e. Housing services, which include expenditure on nannies, house help, drivers, and other domestic services (g1007).

f. Local transport, which does not include personal travel-related expenses (g1008).

g. Telecommunication services, which include expenditure on telephone, internet, and network fees (g1009).

h. Cultural and entertainment expenditures, which include expenditure on newspapers, magazines, CDs, movie tickets, dance halls, cafes, and other entertainment-related areas (but excludes expenditure on cards, mahjong, and other gambling-related expenses) (g1010). 


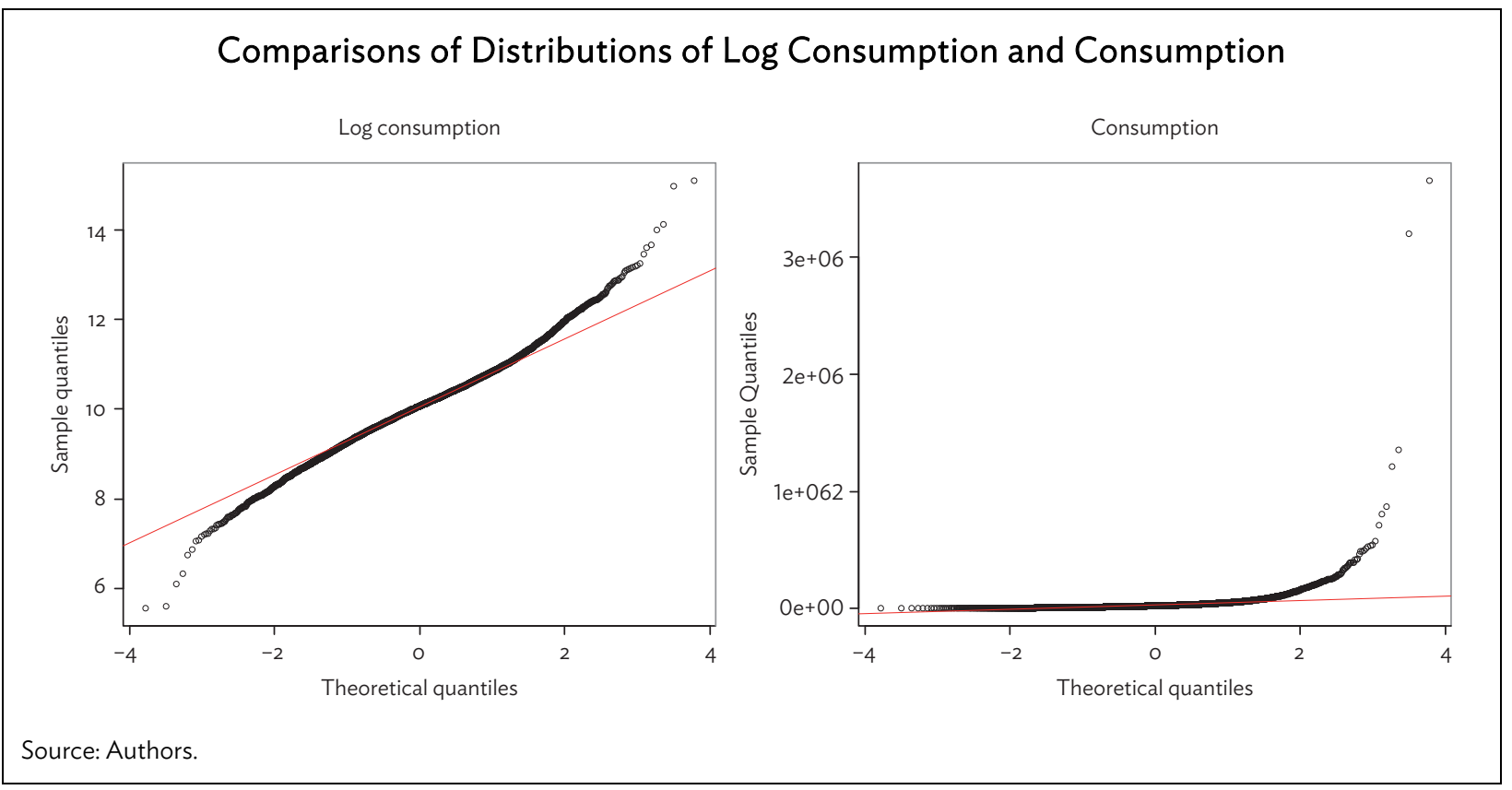

\section{Regression of Income on Household Age Components}

\begin{tabular}{|c|c|c|c|c|c|}
\hline & Bangladesh & Cambodia & PRC & Thailand & Viet Nam \\
\hline Intercept $\boldsymbol{\theta}_{\mathbf{1}}$ & $\begin{array}{c}7.187^{*} \\
(0.065)\end{array}$ & $\begin{array}{l}12.149^{*} \\
(0.05)\end{array}$ & $\begin{array}{l}9.006^{*} \\
(0.12)\end{array}$ & $\begin{array}{r}9.566^{*} \\
(0.029)\end{array}$ & $\begin{array}{l}14.826^{*} \\
(0.041)\end{array}$ \\
\hline No. of young $\left(\boldsymbol{\gamma}_{\mathbf{1}}\right)$ & $\begin{array}{c}-0.012 \\
(0.015)\end{array}$ & $\begin{array}{l}0.065^{*} \\
(0.01)\end{array}$ & $\begin{array}{c}-0.007 \\
(0.04)\end{array}$ & $\begin{array}{l}0.09^{*} \\
(0.01)\end{array}$ & $\begin{array}{l}0.088^{*} \\
(0.01)\end{array}$ \\
\hline No. of middle age $\left(\boldsymbol{\gamma}_{2}\right)$ & $\begin{array}{c}0.334^{*} \\
(0.016)\end{array}$ & $\begin{array}{c}0.186^{*} \\
(0.009)\end{array}$ & $\begin{array}{c}0.147^{*} \\
(0.018)\end{array}$ & $\begin{array}{c}0.249^{*} \\
(0.007)\end{array}$ & $\begin{array}{c}0.245^{*} \\
(0.007)\end{array}$ \\
\hline No. of old $\left(\gamma_{3}\right)$ & $\begin{array}{c}-0.202^{*} \\
(0.081)\end{array}$ & $\begin{array}{c}-0.139 * \\
(0.048)\end{array}$ & $\begin{array}{l}-1.176^{*} \\
(0.06)\end{array}$ & $\begin{array}{c}-0.125^{*} \\
(0.018)\end{array}$ & $\begin{array}{c}-0.324^{*} \\
(0.025)\end{array}$ \\
\hline Dummy $\boldsymbol{\gamma}_{2}{ }^{11}{ }^{*}$ No. of middle aged $\left(\boldsymbol{\gamma}_{2}\right)$ & $\begin{array}{c}-0.029^{*} \\
(0.014)\end{array}$ & $\begin{array}{c}0.00 \\
(0.008)\end{array}$ & $\begin{array}{c}0.024 \\
(0.018)\end{array}$ & $\begin{array}{c}-0.057^{*} \\
(0.007)\end{array}$ & $\begin{array}{c}0.002 \\
(0.007)\end{array}$ \\
\hline Dummy $\boldsymbol{\gamma}_{3}{ }^{12}$ * No. of elderly $\left(\boldsymbol{\gamma}_{3}\right)$ & $\begin{array}{r}0.441^{*} \\
(0.086)\end{array}$ & $\begin{array}{c}0.156^{*} \\
(0.051)\end{array}$ & $\begin{array}{c}0.994^{*} \\
(0.066)\end{array}$ & $\begin{array}{l}0.226^{*} \\
(0.02)\end{array}$ & $\begin{array}{c}0.447^{*} \\
(0.027)\end{array}$ \\
\hline $\begin{array}{l}\text { Adjusted R-squared } \\
\text { No. of observations }\end{array}$ & $\begin{array}{l}0.099 \\
11,210\end{array}$ & $\begin{array}{r}0.193 \\
11,348\end{array}$ & $\begin{array}{l}0.238 \\
6,359\end{array}$ & $\begin{array}{r}0.109 \\
43,530 \\
\end{array}$ & $\begin{array}{l}0.314 \\
9,395\end{array}$ \\
\hline
\end{tabular}

PRC = People's Republic of China.

Note: ${ }^{*}$ denote significance at the $10 \%$ level.

Source: Authors.

1 Dummy $=1$ if the households are with young member.

12 Dummy $=1$ if the elderly members live with their children. 


\section{REFERENCES}

Alessie, Rob, and Joppe de Ree. 2009. "Explaining the Hump in Life Cycle Consumption Profiles.” De Economist 157 (1): 107-20.

Cutler, David M., James M. Poterba, Louise M. Sheiner, and Lawrence H. Summers. 1990. “An Aging Society: Opportunity or Challenge?" Brookings Papers on Economic Activity. 1: 1-73.

Deaton, Angus. 1997. The Analysis of Household Surveys: A Microeconometric Approach to Development Policy. Baltimore and London: The Johns Hopkins University Press.

Erlandsen, Solveig, and Ragnar Nymoen. 2008. "Consumption and Population Age Structure." Journal of Population Economics 21 (3): 505-20.

Han, Xuehui. 2010. "Housing Demand in Shanghai: A Discrete Choice Approach." China Economic Review 21 (2): 355-76.

Kniesner, Thomas J., W. Kip Viscusi, and James P. Ziliak. 2006. "Life-Cycle Consumption and the AgeAdjusted Value of Life." The B.E. Journal of Economic Analysis \& Policy 5(1). https://doi.org/10.1515/1538-0645.1524.

Mankiw, N. Gregory, and David N. Weil. 1989. "The Baby Boom, the Baby Bust, and the Housing Market." Regional Science and Urban Economics 19 (2): 235-58.

Prskawetz, Alexia, and Jože Sambt. 2014. "Economic Support Ratios and the Demographic Dividend in Europe." Demographic Research 30 (34): 963-1010.

Weil, David N. 1999. "Population Growth, Dependency, and Consumption.” The American Economic Review 89 (2): 251-55.

World Bank. 2017a. Household Final Consumption Expenditure, etc. http://data.wordlbank.org/indicator/ne.con.petc.zs.

2017b. Household Final Consumption Expenditure. http://data.worldbank.org/indicator/ ne.con.prvt.cd. 


\section{Consumption- and Productivity-Adjusted Dependency Ratio with Household Structure Heterogeneity}

Population aging, now a new norm for almost all emerging economies, brings paramount challenges including increasing consumption burden from elderly people. A comprehensive policy reform, guided by a more scientific version of the dependency ratio, is needed to accommodate this new norm. This paper presents a new dependency ratio measure that takes into account the consumption needs of the young and elderly people, and the productivity of middle-aged people. Using household survey data from Bangladesh, Cambodia, the People's Republic of China, Thailand, and Viet Nam, this paper estimates the factor of relative needs of people at different ages based on a regression model.

\section{About the Asian Development Bank}

ADB's vision is an Asia and Pacific region free of poverty. Its mission is to help its developing member countries reduce poverty and improve the quality of life of their people. Despite the region's many successes, it remains home to a large share of the world's poor. ADB is committed to reducing poverty through inclusive economic growth, environmentally sustainable growth, and regional integration.

Based in Manila, ADB is owned by 67 members, including 48 from the region. Its main instruments for helping its developing member countries are policy dialogue, loans, equity investments, guarantees, grants, and technical assistance. 